\title{
Development of Lead-Free Machinable Brass with Bismuth and Graphite Particles by Powder Metallurgy Process
}

\author{
Hisashi Imai ${ }^{1}$, Li Shufeng ${ }^{1}$, Haruhiko Atsumi ${ }^{1, *}$, Yoshiharu Kosaka $^{2}$, \\ Akimichi Kojima ${ }^{2}$ and Katsuyoshi Kondoh ${ }^{1}$ \\ ${ }^{1}$ Joining and Welding of Research Institute, Osaka University, Ibaraki 567-0047, Japan \\ ${ }^{2}$ SAN-ETSU METALS CO. LTD., Tonami 939-1315, Japan
}

\begin{abstract}
The aim of this paper was to produce a lead-free machinable brass dispersed with bismuth and graphite particles by powder metallurgy process. The effect of the machinable elements on the elongation and machinability of extruded materials was investigated. The $\mathrm{Cu}-40 \mathrm{mass} \% \mathrm{Zn}$ $(\mathrm{Cu}-40 \mathrm{Zn}$ ) brass powder with $0 \sim 3.23$ mass \% bismuth additions were produced by rapid solidification process, having a mean particle size of $150 \mu \mathrm{m}$. It was found that bismuth were uniformly dispersed as the island of about $5 \mathrm{um}$ in the brass powder matrix, and appeared at the brass powder surface after heat treatment over the melting point of bismuth. When 2.2 mass $\%$ or more bismuth was added, the quantity of bismuth appearing at the brass powder surface increased because of saturated quantity of bismuth elements in the brass powder. There were bismuth islands of tens of microns in the extruded brass with 2.2 mass $\%$ or more bismuth addition. These bismuth islands were depressed the elongation of extruded materials. The graphite particles with mean particle size of $5 \mu \mathrm{m}$ were also used as raw powder. $0 \sim 0.5$ mass $\%$ graphite particles were mixed with the as-atomized brass powder by dry process. The elongation of the extruded brass alloy with both bismuth and graphite particles additions increased comparing with that of extruded brass with bismuth addition. The extruded brass using the as-atomized brass powder with 2.2 mass $\%$ bismuth and 0.5 mass $\%$ graphite particles indicated excellent machinability as well as the conventional leaded brass. Synergy effect of bismuth and graphite particles on the improvement of elongation and machinability of brass alloys was much useful compared with the brass containing only bismuth or graphite particles. [doi:10.2320/matertrans.MH200907]
\end{abstract}

(Received November 2, 2009; Accepted January 15, 2010; Published April 25, 2010)

Keywords: lead-free, $\mathrm{Cu}-40 \mathrm{Zn}$ brass, bismuth, graphite particles, machinability

\section{Introduction}

Brasses are widely used as an industrial material because of its excellent characteristics such as high corrosion resistance, non-magnetism, good machinability and good plastic deformability. 2-5 mass $\%$ lead is added to the traditional brass to improve its machinability. ${ }^{1-3)}$ Unfortunately, lead addition in the materials was found to cause severe hazard to environment and human health. ${ }^{4,5)}$ Bismuth (Bi), silicon ( $\mathrm{Si}$ ), selenium ( $\mathrm{Se})$, and graphite particles as alternative elements to lead have been discussed to improve machinability of brass. ${ }^{6-10)}$ Graphite particle is a common solid lubricant and has an abrasive character, ${ }^{11-13)}$ which is available to be used as an additive to brass alloys because it is cheap and environmentally benign. It is, however, very difficult to uniformly disperse graphite particles in the brass matrix by ingot metallurgy (I/M) process due to the significantly large difference in the density between graphite and brass alloy, and to the floating of graphite by adhering to vaporized zinc $(\mathrm{Zn})$ in heating and casting. ${ }^{14)}$ On the other hand, bismuth has similar properties to lead such as melting point, solid solubility to the copper, and density. Bismuth dose not cause side-effect to environment and human health. However, bismuth exists as several tens of microns in brass cast ingot, and results in depressing the machinability and elongation of brass alloys comparing with the traditional leaded brass. ${ }^{15,16)}$ Cracks are also generated from such coarse bismuth islands as the secondary dispersed phase.

In this paper, a new lead-free machinable brass dispersed with bismuth and graphite particles was produced by powder metallurgy $(\mathrm{P} / \mathrm{M})$ process. Bismuth distribution in brass powder prepared by rapid solidification process was exam-

*Graduate Student, Osaka University ined, and the effect of the distribution of bismuth on the elongation and machinability of extruded materials was investigated. Furthermore, the mechanical properties and machinability of brass with both bismuth and graphite particle additions was compared with that of brass containing bismuth. Finally, the synergy effect of bismuth and graphite particles additions on the improvement of mechanical properties and machinability of brass alloys was investigated.

\section{Experimental Procedure}

$\mathrm{Cu}-40$ mass $\% \mathrm{Zn}(\mathrm{Cu}-40 \mathrm{Zn})$ alloy powder containing bismuth elements was prepared by the water atomization, having a mean particle size of about $150 \mu \mathrm{m}$. The bismuth additions to brass were $0,1.0,2.2,2.62,2.91$, and 3.23 mass $\%$, respectively. The microstructure changes due to thermal behavior of the as-received powder during annealing was investigated by differential thermal analysis (DTA) and thermo-gravimetric analysis (TG) (DTG-60: SHIMADZU Co.) under a heating rate of $0.17 \mathrm{~K} / \mathrm{s}$ and $0.03 \mathrm{~K} / \mathrm{s}$ in Ar gas atmosphere from room temperature up to $1273 \mathrm{~K}$. Graphite, having a mean particle size of $5 \mu \mathrm{m}$, was prepared as a machinable element. $0,0.25$, and 0.5 mass $\%$ graphite particles were added to the as-atomized powders (1.0 and 2.2 mass \% Bi), respectively. The as-atomized powder and graphite particles were elemental mixed by the ball milling machine (AV-2: ASAHIRIKA) for $14.4 \mathrm{~h}$ under $120 \mathrm{rpm}$.

SPS (SPS-1030: SPS SYNTEX INC.) was used to consolidate the above elemental mixed powders with different additive of graphite particles. The consolidation of the high-density sintered compact was preformed using the temperature of $1053 \mathrm{~K}$ for $1.8 \mathrm{ks}$ under $40 \mathrm{MPa}$ pressure in vacuum. ${ }^{17)}$ Cast ingot billets with the same bismuth content were prepared for extrusion as a comparison. 
Each billet was preheated at $873 \mathrm{~K}$ for $180 \mathrm{~s}$ in $\mathrm{Ar}$ gas atmosphere using a heating rate of $0.65 \mathrm{~K} / \mathrm{s}$ in a muffle furnace (KDF S-70: DENKEN Co.) before extrusion. Then, it was immediately extruded by using the hydraulic press machine (2000 kN SHP-200-450: SHIBAYAMAKIKAI Co.) under an extrusion ratio of 37.

The microstructural observation by scanning electron microscopy (SEM, JSM-6500F: JEOL) equipped with Xray energy dispersive spectroscopy (EDS EX-64175JMU: JEOL) was carried out on the consolidated specimens to investigate the morphology and distribution of machinable elements. Mechanical properties of extruded materials were evaluated by a tensile testing machine (Autograph AG-X $50 \mathrm{kN}$ : SHIMADZU) under a strain rate of $5 \times 10^{-4} \mathrm{~s}^{-1}$. The machinability of $\mathrm{Cu}-40 \mathrm{Zn}$ brass alloys was evaluated by a drilling test using a drill tool (EX-SUS-GDS: OSG Co.), having a $4.5 \mathrm{~mm}$ diameter, under dry conditions. The rotation speed of the drill was $900 \mathrm{rpm}$, and applied load during drilling was $9.8 \mathrm{~N}$. The drilling time to make a hole with a $5 \mathrm{~mm}$ depth was measured. After repeating this drilling test 10 times, the average drilling time was used as a machinability parameter of the specimen.

\section{Results and Discussion}

Figure 1 shows DTA-TG profiles of raw brass powder with and without bismuth. Weight loss was detected in both TG results from $903 \mathrm{~K}$ which is caused by zinc evaporation. ${ }^{17)}$ Exothermic heat reaction at $623 \mathrm{~K}$ and endothermic heat reaction at $723 \mathrm{~K}$ were detected in both DTA results. Raw powders were produced by using a rapid solidification process, and contained only the $\beta^{\prime}$ phase. The exothermic reaction at $623 \mathrm{~K}$ corresponds to the transformation from the $\beta^{\prime}$ phase to the $\alpha$ phase. On the other hand, the endothermic reaction at $723 \mathrm{~K}$ corresponds to the transformation from the $\beta^{\prime}$ phase to the $\beta$ phase. ${ }^{18)}$ The unique behavior of DTA in row powder with bismuth was the endothermic reaction at $443 \mathrm{~K}$, which corresponded to the melting of bismuth.

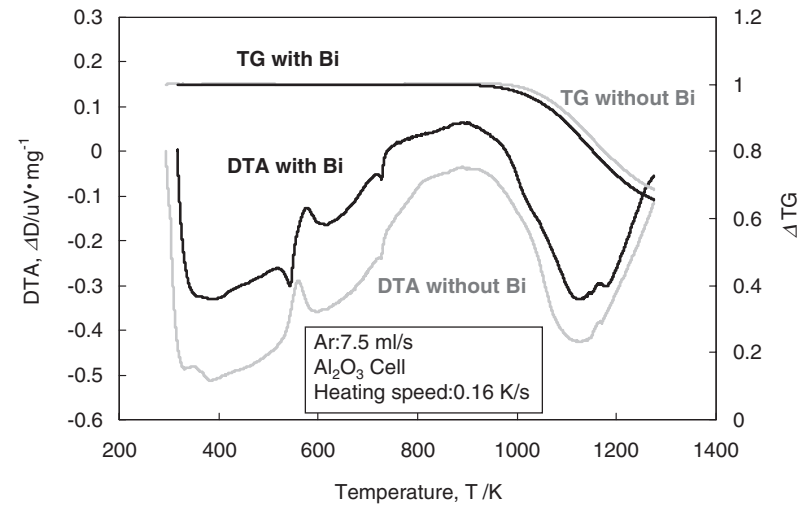

Fig. 1 Thermo gravimetric analysis and differential thermal analysis profiles of $\mathrm{Cu}-40 \mathrm{Zn}$ brass powder with and without bismuth.

Figure 2 shows SEM-EDS observations on the cross section of brass powder with bismuth. Each powder was heated at $1023 \mathrm{~K}$ for $1.8 \mathrm{ks}$ in Ar gas atmosphere using a heating rate of $0.65 \mathrm{~K} / \mathrm{s}$ in a muffle furnace. Bismuth could not be observed which means bismuth was not appeared in the as-atomized brass matrix (a). It was considered that bismuth was compulsorily dissolved in brass matrix by using a rapid solidification process. After heat treatment, bismuth were uniformly dispersed as the islands of about $5 \mu \mathrm{m}$ in the brass powder matrix, and appeared at the brass powder surface. In the brass matrix, bismuth islands segregated to the brass grain boundaries. The phenomenon was also reported by A. La Fontaine. ${ }^{19)}$ It was considered that supersaturated bismuth in the brass powder liquated out at heat temperature over the melting point of bismuth and it solidified inside or outside brass powder during the cooling process. Bismuth quantity appearing at brass powder surface showed higher value for powder with 2.62 mass\% bismuth additions (c), compared with the powder with 2.2 mass $\%$ bismuth additions (b). On the other hand, the area ratio of bismuth islands in the powder with 2.2 mass $\%$ bismuth was almost equal to that in brass powder with 2.62 mass \% bismuth (c). When using brass with 2.2 mass \% or more bismuth, the quantity of bismuth
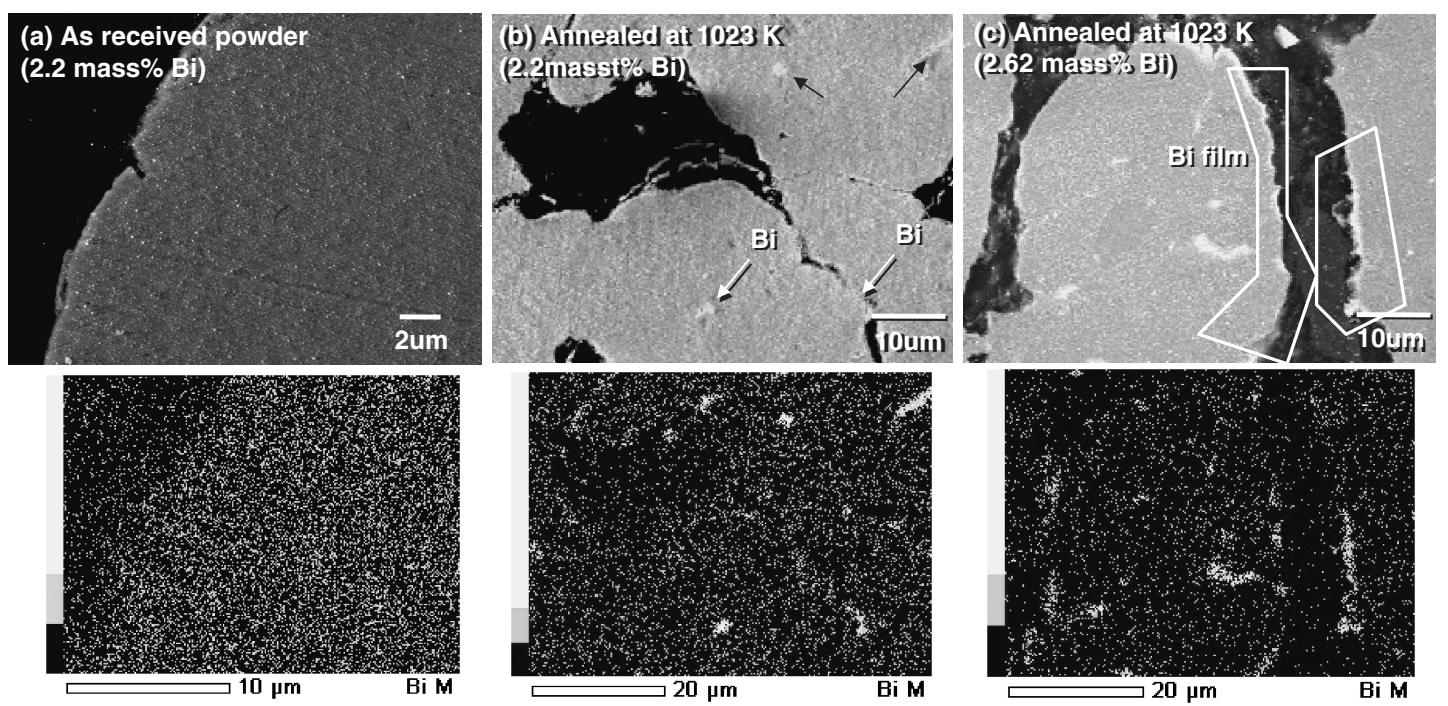

Fig. 2 SEM-EDS observation on the cross section of as atomized powder and annealed powder of Cu-40Zn alloys with bismuth. 

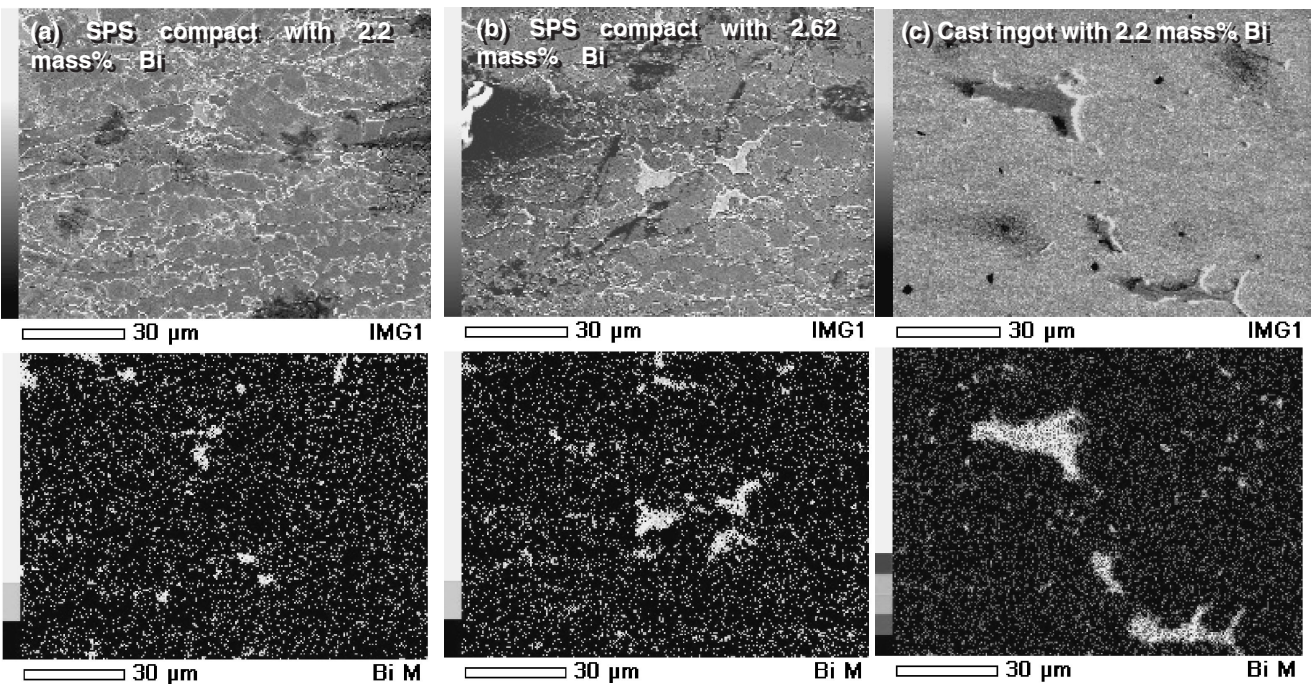

Fig. 3 SEM-EDS observation of extruded $\mathrm{Cu}-40 \mathrm{Zn}$ alloys with bismuth using $\mathrm{P} / \mathrm{M}$ and $\mathrm{I} / \mathrm{M}$ billets.

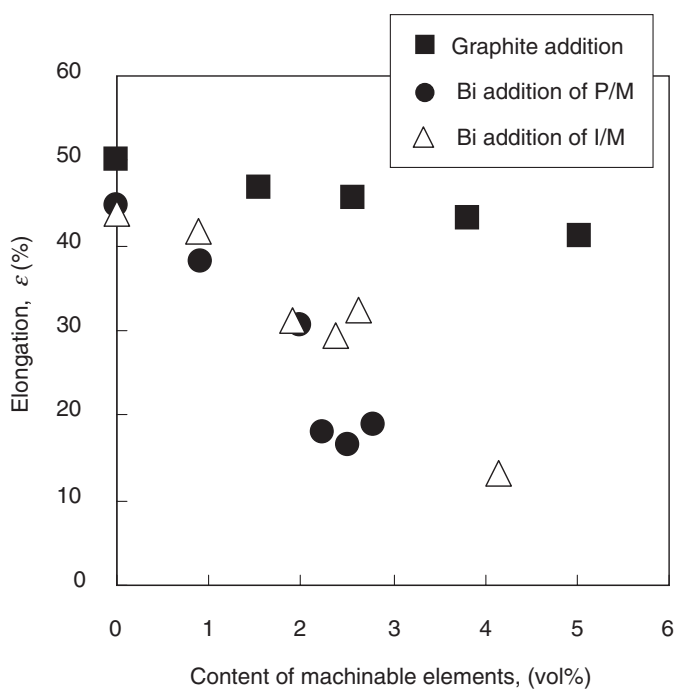

Fig. 4 Dependence of the elongation on volume fraction of machinable elements of extruded $\mathrm{P} / \mathrm{M}$ and $\mathrm{I} / \mathrm{M} \mathrm{Cu}-40 \mathrm{Zn}$ alloys.

appearing at the brass powder surface increased because of the saturated quantity of the bismuth in the brass powder.

Figure 3 shows SEM-EDS observation of extruded brass using $\mathrm{P} / \mathrm{M}$ and $\mathrm{I} / \mathrm{M}$ billets with bismuth. Bismuth islands of about 5 um size dispersed in the extruded materials using $\mathrm{P} / \mathrm{M}$. There were bismuth islands of tens of microns in the extruded materials with 2.62 mass $\%$ bismuth additions. It was considered that the bismuth islands of tens of microns were formed by the bismuth appearing at the brass powder surface. On the other hand, bismuth islands with 20-30 $\mu \mathrm{m}$ diameter was ununiformly distributed in the extruded material of cast billet (c). These bismuth islands over $10 \mu \mathrm{m}$ would cause the reducing tensile ductility.

Figure 4 shows dependence of the elongation on the volume fraction of machinable elements in extruded $\mathrm{P} / \mathrm{M}$ and $\mathrm{I} / \mathrm{M} \mathrm{Cu}-40 \mathrm{Zn}$ alloys. The results of extruded brass with only graphite particles were also shown in same figure. ${ }^{20)}$ Bismuth addition has more influence on the elongation than the graphite particle addition. The elongation of $\mathrm{P} / \mathrm{M}$ extruded

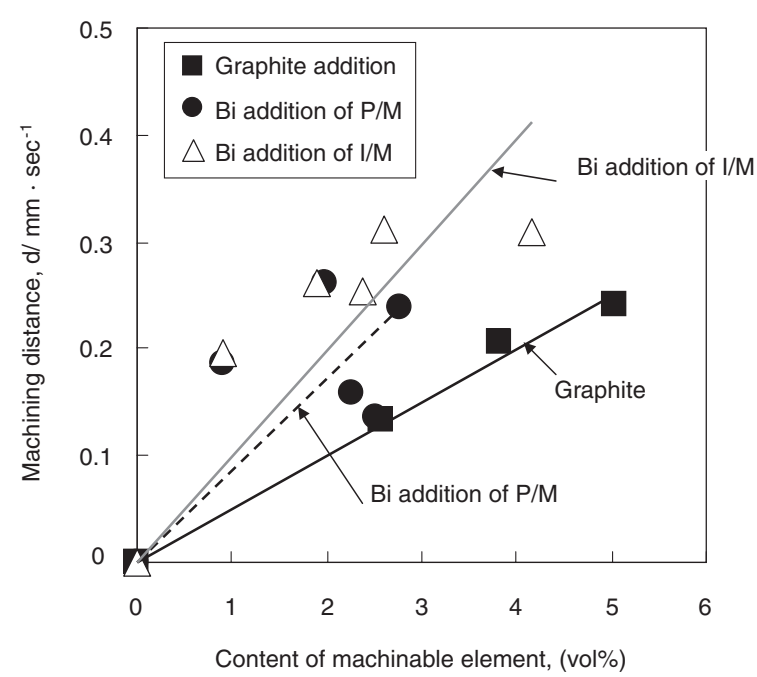

Fig. 5 Dependence of the machining distance on machinable elements content of extruded $\mathrm{P} / \mathrm{M}$ and $\mathrm{I} / \mathrm{M} \mathrm{Cu}-40 \mathrm{Zn}$ alloys.

brass with more than 2.2 mass $\%$ (1.99 vol\%) bismuth addition showed remarkably decrease. From the observation of fractured surface of tensile test specimens, there were brittle fracture areas of the size of tens of microns on the specimen of the brass with 2.62 mass $\%$ bismuth additions. Bismuth was detected in the area by EDS analysis. The bismuth islands of tens of microns depressed the elongation of extruded materials. On the other hand, ultimate tensile strength (UTS) of extruded brass with machinable elements was around $400 \mathrm{MPa}$ regardless of the kind and quantity of machinable elements.

Figure 5 shows the machinability of extruded brass alloys with bismuth by drilling tests. It was evaluated by machining distance per unit time. Bismuth addition has more effective of the machinability than graphite particle addition. As the results of the elongation and machinability, the $\mathrm{P} / \mathrm{M}$ brass alloys by using the mixed powder was expected to achieve the lead-free machinable brass with good balance between the elongation and the machinability. 


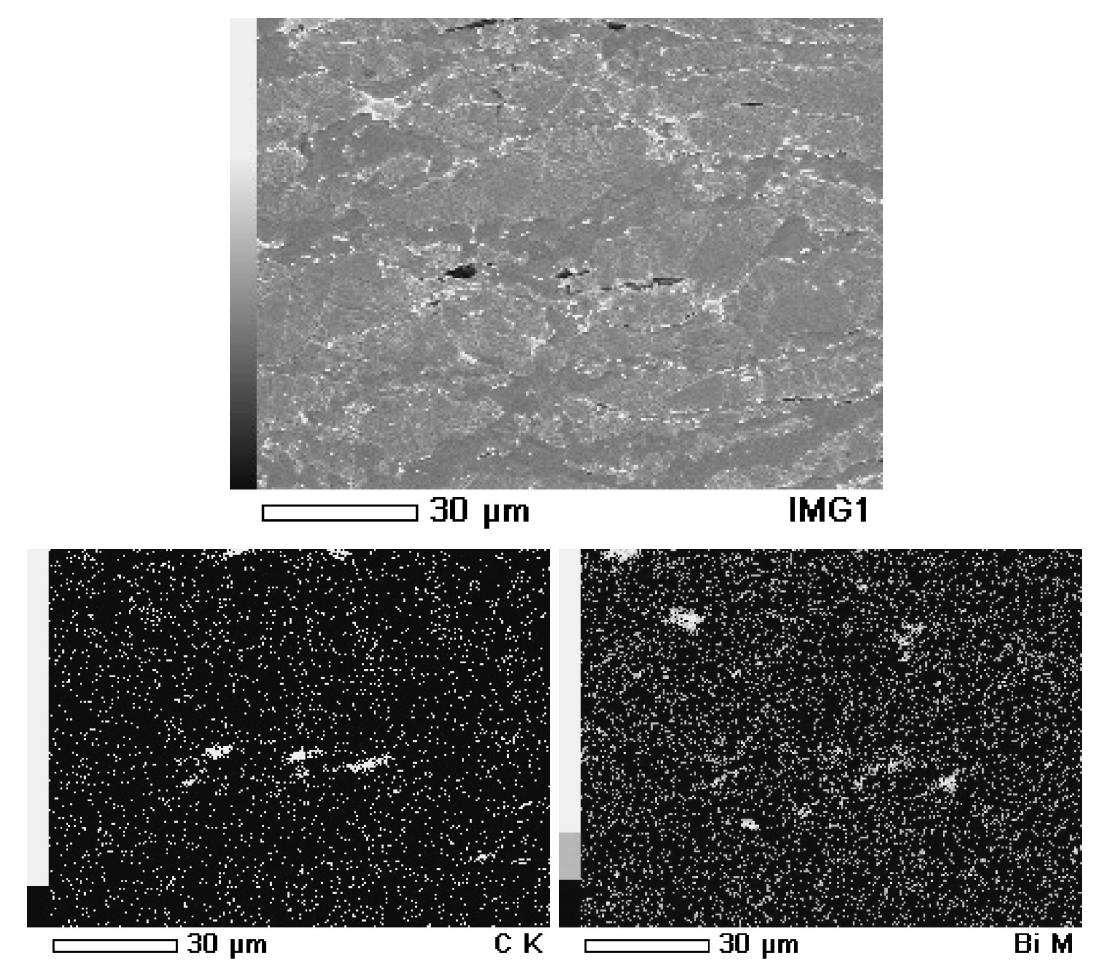

Fig. 6 SEM-EDS observation of extruded $\mathrm{Cu}-40 \mathrm{Zn}$ alloys with 2.2 mass\% bismuth and 0.5 mass $\%$ graphite particles.

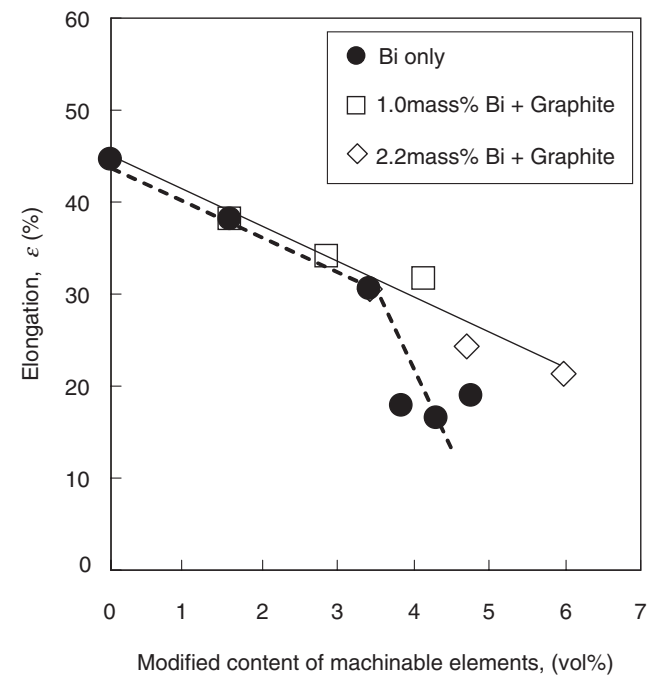

Fig. 7 Dependence of the elongation on modified content of machinable elements in extruded $\mathrm{P} / \mathrm{M}$ and $\mathrm{I} / \mathrm{M} \mathrm{Cu}-40 \mathrm{Zn}$ alloys.

Figure 6 shows SEM-EDS observation of extruded brass with 2.2 mass $\%$ bismuth and 0.5 mass $\%$ graphite particles. Bismuth islands of about 5-10 um dispersed in the extruded materials. On the other hand, there was not any bismuth island of tens of microns in the extruded materials. It was found that the bismuth and graphite particles existed independently in the extruded materials by using mixed powder. The graphite addition indicated no influence in the distribution of bismuth.

Figure 7 shows dependence of the elongation on volume fraction of machinable elements in extruded $\mathrm{P} / \mathrm{M} \mathrm{Cu}-40 \mathrm{Zn}$ alloys. The brass with graphite particles was considered as a machinability rate standard from the result of Fig. 5. The

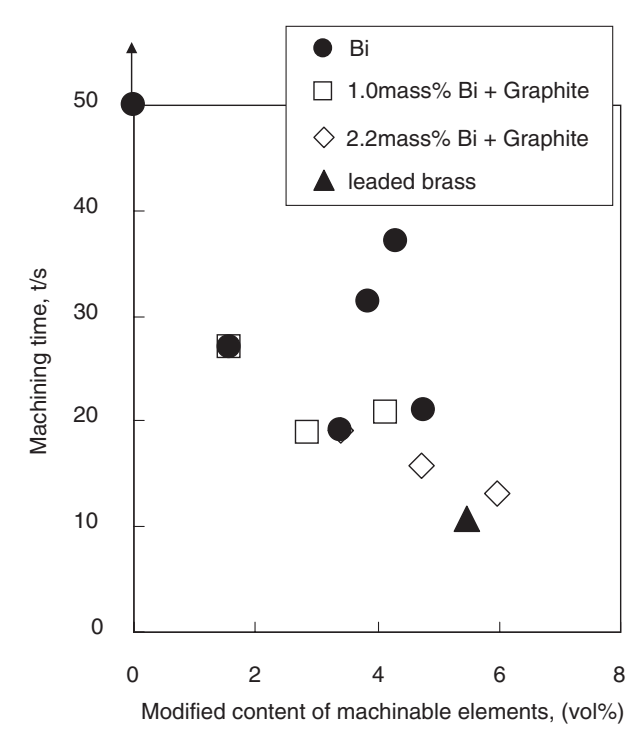

Fig. 8 Dependence of the machining time on modified content of machinable elements in extruded $\mathrm{P} / \mathrm{M}$ and $\mathrm{I} / \mathrm{M} \mathrm{Cu}-40 \mathrm{Zn}$ alloys.

bismuthal $1 \%$ volume fraction was correspondent to the graphitic $1.71 \%$ volume fraction by using the definition. The elongation of the brass with both bismuth and graphite particles additions kept $20 \%$. It was considered that there was not any bismuth island of tens of microns in the primary particle boundaries.

Figure 8 shows dependence of the machining time on volume fraction of machinable elements in extruded brass alloys. The data for $\mathrm{Cu}-\mathrm{Zn}-3.2$ mass\% $\mathrm{Pb}$ (conventional machinable brass), are also plotted as reference. ${ }^{17)}$ The average drilling time decreases with increasing both bismuth and graphite particles contents. $\mathrm{P} / \mathrm{M}$ extruded brass alloys 
with 0.5 mass $\%$ graphite particles and 2.2 mass $\%$ bismuth additions had excellent machinability as well as the leaded brass. This material had $388 \mathrm{MPa}$ UTS and $21 \%$ elongation. The lead-free machinable brass with good balance between the elongation and the machinability was obtained by using the brass powder with 2.2 mass $\%$ or less bismuth addition and graphite particles.

\section{Conclusions}

A new lead-free machinable brass dispersed with bismuth and graphite particles by powder metallurgy process was produced. The effect of bismuth and graphite particles in the brass alloys on the mechanical properties and machinability of extruded materials was investigated. The results in this study are summarized as follows.

(1) Bismuth was uniformly dispersed as island of about $5 \mu \mathrm{m}$ in the brass powder matrix, and appeared at the brass powder surface after heat treatment over the melting point of bismuth. When 2.2 mass $\%$ or more bismuth added, the quantity of bismuth appearing at the brass powder surface increased.

(2) Bismuth addition was more influence of reducing the elongation than the graphite particle addition. There were bismuth islands of tens of microns in primary particle boundaries. The bismuth islands depressed the elongation of extruded materials. The elongation of $\mathrm{P} / \mathrm{M}$ extruded brass with more than 2.2 mass \% bismuth additions remarkably decreased because of increasing the bismuth islands of tens of microns.

(3) The bismuth elements and graphite particles existed independently in the extruded materials by using the brass powder with 2.2 mass $\%$ or less bismuth additions and graphite particles. $\mathrm{P} / \mathrm{M}$ extruded brass alloys with 0.5 mass $\%$ graphite particles and 2.2 mass $\%$ bismuth additions had excellent machinability as well as the leaded brass. This material had $388 \mathrm{MPa}$ UTS and $21 \%$ elongation. The lead-free machinable brass with the good balance between the elongation and the machinability was obtained by using the mixed powder.

\section{Acknowledgement}

This work was supported by a "Grant for Practical Application of University R\&D results under the Matching Fund Method (2009)", New Energy and Industrial Technology Development Organization (NEDO) and "Comprehensive Support Programs for Creation of Regional Innovation (2009)" Japan Science and Technology Agency (JST).

\section{REFERENCES}

1) A. French: J. Inst. Met. 101 (1973) 125-137.

2) JCBA: Base and Industrial technology of copper and copper alloys, (1994) pp. 538-539.

3) P. García, S. Rivera, M. Palacios and J. Belzunce: Eng. Failure Analysis, doi: 10.1016/j.engfailanal.2009.08.012

4) X. Chen, A. Hu, M. Li and D. Mao: J. Alloy. Compd. 460 (2008) 478484.

5) S. Kuyucak and M. Sahoo: Can. Metall. Quart. 35 (1996) 1-15.

6) L. Whiting, P. Newcombe and M. Sahoo: AFS Trans. 103 (1995) 683691.

7) D. Peter: Mod. Casting 87 (1997)

8) K. Kondoh, Y. Kosaka, M. Okuyama and A. Kojima: Collected Abstracts of 46th technology conference of Japan Copper and Brass Association (2006) pp 153-154.

9) A. Sigal and P. Rohatgi: AFS Trans. 104 (1996) 225-228.

10) C. Vilarinho, J. P. Davim, D. Soares, F. Castro and J. Barbosa: J. Mater. Process. Technol. 170 (2005) 441-447.

11) G. Cabral, P. Reis, R. Polini, E. Titus, N. Ali, J. P. Davim and J. Grácio: Diamond Related Mater. 15-10 (2006) 1753-1758.

12) B. Suresha, Siddaramaiah, Kishore, S. Seetharamu and P. Sampath Kumaran: Wear 267 (2009) 1405-1414.

13) H. Zhao, L. Liu, Y. Wu and W. Hu: Comp. Sci. 67 (2007) 1210-1217.

14) T. Kobayashi, T. Maruyama and K. Nakao: J. JRICu 42 (2003) 217228.

15) Kyoto Brass Co., Ltd: JP 2008-214760 (2008).

16) H. Imai, S. Li, H. Atsumi, Y. Kosaka, A. Kojima and K. Kondoh: Trans. JWRI 38 (2009) 25-30.

17) H. Imai, K. Kondoh, Y. Kosaka, A. Kojima, G. Katano and J. Umeda: J. Jpn. Soc. Powder Powder Metall. 55 (2008) 746.

18) JCBA: Base and Industrial technology of copper and copper alloys, (1994) p 224.

19) A. La Fontaine and V. J. Keast: Mater. Charact. 57 (2006) 424-429.

20) H. Imai, K. Kondoh, Y. Kosaka, A. Kojima and G. Katano: Trans. JWRI 37 (2008) 51-56. 